\title{
Additional Nodal Disease Prediction in Breast Cancer with Sentinel Lymph Node Metastasis Based on Clinicopathological Features
}

\author{
PAOLO ORSARIA ${ }^{1}$, EMANUELE CAREDDA ${ }^{2}$, FEDERICA GENOVA ${ }^{1}$, MARCO MATERAZZO $^{1}$, \\ ILARIA CAPUANO ${ }^{1}$, GIANLUCA VANNI $^{1}$, ALESSANDRA VITTORIA GRANAI $^{1}$, \\ ADRIANO DE MAJO ${ }^{1}$, ILARIA PORTARENA ${ }^{3}$, PIERPAOLO SILERI ${ }^{1}$, \\ GIUSEPPE PETRELLA ${ }^{1}$, LEONARDO PALOMBI $^{2}$ and ORESTE CLAUDIO BUONOMO ${ }^{1}$ \\ Departments of ${ }^{1}$ Surgery, and ${ }^{2}$ Biomedicine and Prevention, and \\ ${ }^{3}$ Medical Oncology Unit, Department of Internal Medicine, Tor Vergata University Hospital, Rome, Italy
}

\begin{abstract}
Aim: The standard-of-care in breast cancer (BC) with positive sentinel lymph node (SLN) metastasis includes complete axillary lymph node dissection (ALND); however, almost half of such cases have no further tumor burden. This study aimed to assess the clinicopathological factors that predict non-SLN metastasis to define subgroups of SLNpositive patients in whom the axilla may be staged by SLN biopsy alone, while avoiding unnecessary overtreatment. Patients and Methods: The records of 191 patients with histologically-proven primary $B C$ who underwent a positive (SLN) biopsy between 2005 and 2017 were reviewed. Patients with at least one tumor-involved SLN who underwent completion ALND were enrolled. Demographic and clinicopathological characteristics, including age, primary tumor size and histological grade, lymphovascular invasion, ratio of positive SLNs to the harvested SLNs, SLN metastasis size, and molecular subtype classification according to immunohistochemical biomarker status [estrogen receptor $(E R)$, progesterone receptor $(P R)$, and human epidermal growth factor receptor 2 (HER2)], were evaluated. Data were collected retrospectively and analyzed using the Mann-Whitney and Chi-square tests (statistical significance: $p<0.05)$. Results: The incidence of non-SLN metastasis associated with positive SLN was $48.6 \%$ (93/191). The risk of additional nodal spread correlated with high sentinel nodal ratio $>0.67$ [odds ratio $(O R)=2.55$, $p=0.032]$, luminal $B C$ subtype $(O R=2.67, p=0.06), H E R 2$ overexpression $(O R=0.4, p=0.016)$, and $E R^{+} P R^{-} H E R 2^{-}$
\end{abstract}

Correspondence to: Paolo Orsaria, Department of Surgery, Tor Vergata University Hospital, 81 Oxford Street, 00133 Rome, Italy. E-mail: orsaria@aol.it

Key Words: Breast neoplasms, nodal metastasis, sentinel lymph node. profile $(O R=2.95, p=0.027)$. There was a tendency (statistically insignificant; $p>0.05$ ) toward higher incidence of non SLN metastasis with increasing age and histological grade, which could be attributed to the small sample size. Conclusion: According to this study, sentinel nodal ratio and BC subtypes as per ER, PR, and HER2 status significantly predicted the likelihood of additional lymphatic involvement. Validation of these parameters in prospective studies is indicated, and may help individualize treatment modalities.

Among patients with breast cancer (BC), the probability of distal recurrence increases progressively with the number of axillary nodes involved, and in the context of several molecular signatures (1). The expression status of steroid receptors and human epidermal growth factor receptor 2 (HER2) may predict local aggressiveness and disease dissemination of BC. Axillary lymphatic spread is reported to be higher in estrogen receptor (ER)/progesterone receptor (PR)-positive patients, aiding decisions regarding nodal dissection in positive sentinel lymph node (SLN) biopsy procedures $(2,3)$. However, with short follow-up, HER2 is reported to be prognostic for disease-free and overall survival (OS) in node-positive BC, and with longer follow-up, in node-negative BC as well (4). Furthermore, previous studies have reported a higher risk of nodal involvement in those with triple-positive disease $\left(\mathrm{ER}^{+} \mathrm{PR}^{+} \mathrm{HER} 2^{+}\right)$, suggesting activation of local invasion pathways $(5,6)$. However, the predictive value of steroid receptor expression for lymphatic invasion is controversial because in most cases, other predictive factors such as high grade, large tumor size, and younger age at diagnosis may be concurrent (7).

Various clinicopathological features such as clinical palpability, lymphovascular invasion, Ki-67 receptor status, molecular subtype classification, multifocality, and the 
number of harvested and positive SLNs have been identified as independent predictors of lymphatic involvement in earlystage BC (8-10).

Axillary status is the strongest factor correlated to OS, and is one of the major determinants of therapeutic decisions. It is thought that nodal metastasis correlates well with the intrinsic biological properties of ER ${ }^{-} \mathrm{HER}^{-} \mathrm{BC}$, whereas stochastic events, tumor size, growth rate, and lymphovascular invasion are the main determinants in ER+ or HER2 BC (11-13). The nodal status of patients with ER $^{-}$HER2 ${ }^{-}$BC is independent of tumor size, with a $20 \%$ incidence of axillary metastases. Conversely, in $\mathrm{ER}^{+}$or HER2 ${ }^{+}$BC, a strong and almost linear correlation exists between tumor size and incidence of axillary metastasis (9).

Therefore, owing to its prognostic and therapeutic implications, complete nodal dissection has remained the standard-of-care in patients with positive SLNs. However, several studies have indicated that non-SLN metastasis was observed in only $35 \%$ to $50 \%$ of patients with BC with a positive SLN $(14,15)$. Thus, $50 \%$ to $65 \%$ of patients with positive SLN undergo unnecessary axillary lymph node dissection (ALND), and experience associated morbidities such as hand paresthesia, shoulder dysfunction, and lymphedema (16-18). To stratify patients with positive SLN for ALND, reevaluation of criteria for predicting clinically significant axillary disease burden is required. Indeed, the presence and number of metastatic nodes have major prognostic value and guide adjuvant therapy choices (19). Consequently, avoiding ALND may lead to underdetection of involved nodes and unacceptable undertreatment. With the intent to better define individual therapeutic approaches, the aim of this study was to investigate the association between non-SLN metastasis and clinicopathological factors, as well as intrinsic biological and demographic characteristics, of BC subtypes.

It is important to identify inclusion criteria for customized surgery, considering the distinct predictive molecular traits for additional nodal involvement. We additionally compared the extent of axillary disease, with and without remote metastases, in order to explore relative survival and prognosis over time.

Recognition and appreciation of these clinically distinct BC subgroups may help predict outcomes and provide new insights into disease management.

\section{Patients and Methods}

We reviewed the medical records and pathology reports of 191 patients with histologically-proven primary BC, who underwent a positive SLN biopsy and consequent ALND at our clinic between 2005 and 2017. SLN biopsies were performed using the blue dye method, radiocolloid injection, or a combination of both, by surgeons trained for SLN biopsy. SLN metastasis was detected by frozen sectioning during surgery and standard staining of paraffin sections. ALND was performed if any macrometastases or micrometastases in
SLNs were detected by frozen-section analysis. In the case of falsenegatives, ALND was performed again; however, ALND was avoided in patients with isolated tumor cells. To predict non-SLN metastasis in BC with one or fewer nodes, the following clinicopathological and demographic features were analyzed: age at diagnosis, pathological $\mathrm{T}$ stage, tumor grade, lymphovascular invasion, multifocality as lymph node status, ratio of positive SLNs to harvested SLNs (SNR), and immunohistochemical (IHC) biomarker status (ER, PR, Ki-67, and HER2). As per biomarker expression, tumor status was defined as follows: ER-PR-HER2(triple-negative), ER-PR-HER2+, ER+PR-HER2-, ER+PR-HER2+, $\mathrm{ER}^{+} \mathrm{PR}^{+} \mathrm{HER}^{2}{ }^{-}$, or $\mathrm{ER}^{+} \mathrm{PR}^{+} \mathrm{HER} 2^{+}$(triple-positive). Mean follow-up time of 111 patients $(58.1 \%)$ with complete available information for the assessment of long-term prognosis (as evidenced by remote metastasis development) was $4.8 \pm 3.83$ years (median=4 years; interquartile range $=1.4$ to 7.3 years). Written informed consent was obtained from all patients. Data were collected retrospectively. Exclusion criteria were as follows: ductal carcinoma in situ, palpable regional LNs, neoadjuvant chemotherapy, known allergic reactions to the blue dye or the isotope, previous ipsilateral breast surgery, pregnancy, and distant metastasis at diagnosis.

$\mathrm{BC}$ was considered multifocal if two or more lesions were located in the same quadrant and the distance between each lesion was less than $5 \mathrm{~cm}$. A Multidisciplinary Tumor Board comprising of surgeons, medical oncologists, and radiation oncologists specializing in $\mathrm{BC}$ made treatment decisions by consensus. The size of SLN metastasis was categorized according to the American Joint Committee on Cancer Cancer Staging Manual (seventh edition) (20). Lymph node metastatic lesions were defined as: macrometastases ( $\mathrm{pN} 1$; maximum diameter $\geq 2 \mathrm{~mm}$ ), micrometastases ( $\mathrm{pNmi}$; diameter of $0.2-2 \mathrm{~mm}$ ), or as isolated tumor cells [pNO(i+); diameter $<0.2 \mathrm{~mm}$ or single tumor cells] (21). ER, PR, and HER2 status was established using resected primary tumor or the core biopsy sample. HER2 expression was examined by IHC analysis. A gene amplification assay using fluorescence in situ hybridization (FISH) was used in cases of equivocal HER2 IHC results. Ki-67 protein expression was also examined by IHC, and expressed as percentage positivity. Hematoxylin-eosin staining was used to assess lymphovascular invasion and histological grading, which was defined according to the Scarff-Bloom-Richardson system (22). Intrinsic breast cancer subtypes were identified according to the clinicopathological criteria recommended by the St. Gallen International Expert Consensus Report 2013 (23). Patients were categorized based on the primary tumor receptor status as follows: luminal $\mathrm{A}\left(\mathrm{ER}^{+}\right.$or $\mathrm{PR}^{+}$, and HER2-); luminal B HER2- (ER ${ }^{+}$, HER2- and at least one of Ki-67 "high" or PR "negative or low"); luminal B HER2+ (ER+, HER2overexpressed or amplified, any Ki-67, any PR); HER2 (ER- or $\mathrm{PR}^{-}$, and $\mathrm{HER} 2^{+}$), and basal (ER- or $\mathrm{PR}^{-}$, and HER2 ${ }^{-}$). Tumors were considered HER $2^{+}$only if they were either scored $3^{+}$by IHC (strong, complete membrane staining in $>30 \%$ of cancer cells) or showed HER2 amplification (ratio >2) using FISH. In the absence of positive FISH data, tumors scored $2^{+}$using IHC were considered negative for HER2. Tumors were also classified as luminal or nonluminal according to hormone receptor expression.

Statistical analysis. The associations between non-SLN metastasis and clinicopathological factors (age, invasive tumor size, nuclear grade, lymphovascular invasion, ER, PR and HER2 status, molecular subtypes, and Ki-67 labeling index) were examined. Statistical analyses were performed using the chi-squared test and the Mann-Whitney's $U$-test, and a multivariate analysis was 
Table I. Clinicopathological data of included patients with breast cancer.

\begin{tabular}{|c|c|c|c|c|c|}
\hline \multirow[t]{2}{*}{ Variable } & \multirow[t]{2}{*}{ Statistic } & \multirow{2}{*}{$\begin{array}{c}\text { All patients } \\
\mathrm{n}=191\end{array}$} & \multicolumn{2}{|c|}{ NSLN status } & \multirow[b]{2}{*}{$p$-Value } \\
\hline & & & $\begin{array}{c}\text { Positive } \\
(\mathrm{n}=93,48.6 \%)\end{array}$ & $\begin{array}{c}\text { Negative } \\
(\mathrm{n}=98,51.3 \%)\end{array}$ & \\
\hline \multicolumn{6}{|l|}{ Age } \\
\hline At diagnosis (years) & Average (range) & $58.1(30-87)$ & $58.8(40-87)$ & $57.5(30-84)$ & 0.47 (t-test) \\
\hline median & 56 & 58 & 55 & & \\
\hline$\leq 50$ & $\mathrm{n}(\%)$ & $63(32.9)$ & $27(42.8)$ & $36(57.1)$ & 0.26 \\
\hline$>50$ & $\mathrm{n}(\%)$ & $128(67.1)$ & $66(51.5)$ & $62(48.4)$ & \\
\hline T stage & Average (mm) & 18.2 & 19.5 & 16.9 & 0.06 (t-test) \\
\hline $\mathrm{T} 1 \mathrm{a}$ & $\mathrm{n}(\%)$ & $3(1.6)$ & $1(33)$ & $2(67)$ & \\
\hline $\mathrm{T} 1 \mathrm{~b}$ & $\mathrm{n}(\%)$ & $28(14.7)$ & $9(32.2)$ & $19(67.8)$ & \\
\hline $\mathrm{T} 1 \mathrm{c}$ & $\mathrm{n}(\%)$ & $97(50.8)$ & $49(50.5)$ & $48(49.5)$ & \\
\hline $\mathrm{T} 2$ & $\mathrm{n}(\%)$ & $62(32.4)$ & $33(53.2)$ & $29(46.7)$ & \\
\hline $\mathrm{T} 3$ & $\mathrm{n}(\%)$ & $1(0.5)$ & $1(100)$ & $0(0)$ & \\
\hline $\mathrm{T} 4$ & $\mathrm{n}(\%)$ & $0(0)$ & $0(0)$ & $0(0)$ & \\
\hline Grading & & & & & 0.45 \\
\hline G1 & $\mathrm{n}(\%)$ & $30(15.7)$ & $15(50)$ & $15(50)$ & \\
\hline $\mathrm{G} 2$ & $\mathrm{n}(\%)$ & $110(57.5)$ & $50(45.4)$ & $60(54.6)$ & \\
\hline G3 & $\mathrm{n}(\%)$ & $48(25.1)$ & $27(56.3)$ & $21(43.7)$ & \\
\hline LVI & $\mathrm{n}(\%)$ & $10(5.2)$ & $3(30)$ & $7(70)$ & 0.38 \\
\hline Multifocality & $\mathrm{n}(\%)$ & $26(13.6)$ & $11(42.3)$ & $15(57.7)$ & 0.93 \\
\hline ER & & & & & 0.027 \\
\hline Positive & $\mathrm{n}(\%)$ & $175 / 191(91.6 \%)$ & $88(50.3)$ & $87(49.7)$ & $(\mathrm{OR}=2.95)$ \\
\hline Negative & $\mathrm{n}(\%)$ & $16 / 191(8.3 \%)$ & $5(31.3)$ & $11(68.7)$ & \\
\hline PR & & & & & 0.77 \\
\hline Positive & $\mathrm{n}(\%)$ & $144 / 191(75.3 \%)$ & $71(49.3)$ & $73(50.7)$ & \\
\hline Negative & $\mathrm{n}(\%)$ & $47 / 191(24.6 \%)$ & $22(46.8)$ & $25(53.2)$ & \\
\hline HER2 & & & & & 0.016 \\
\hline Positive & $\mathrm{n}(\%)$ & $43(22.5)$ & $14(32.6 \%)$ & $29(67.4)$ & $(\mathrm{OR}=0.42)$ \\
\hline Negative & $\mathrm{n}(\%)$ & $148(77.5)$ & $79(53.4)$ & 69 (46.6) & \\
\hline Ki67 & & & & & 0.75 \\
\hline$\leq 14 \%$ & $\mathrm{n}(\%)$ & $119 / 191(62.3)$ & $59(49.5)$ & $60(50.5)$ & \\
\hline$>14 \%$ & $\mathrm{n}(\%)$ & $72 / 191(37.6)$ & $34(47.2)$ & $38(52.8)$ & \\
\hline Molecular subtype & & & & & 0.03 \\
\hline Lum A & $\mathrm{n}(\%)$ & $112(58.6)$ & $60(53.6)$ & $52(46.4)$ & \\
\hline Lum B HER2- & $\mathrm{n}(\%)$ & $24(12.6)$ & $14(58.3)$ & $10(41.7)$ & \\
\hline Lum B HER2+ & $\mathrm{n}(\%)$ & $37(19.4)$ & $14(37.8)$ & $23(62.2)$ & \\
\hline HER2 & $\mathrm{n}(\%)$ & $8(4.2)$ & $0(0.0)$ & $8(100)$ & \\
\hline Basal & $\mathrm{n}(\%)$ & $10(5.2)$ & $5(50)$ & $5(50)$ & \\
\hline
\end{tabular}

NSLN: Non-sentinel lymph node; Lum: luminal; HER2: human epidermal growth factor receptor 2; OR: odds ratio; LVI: lymphovascular invasion.

performed using the logistic regression model. Diagnostic accuracy of invasive tumor size was assessed by receiver operating characteristic (ROC) analysis: the area under the ROC curve (AUC) was used to measure model discrimination. Statistical significance was set at $p<0.05$. Confidence intervals (CIs) were set at a $95 \%$ level. All statistical analyses were carried out using SPSS (IBM SPSS V.23; IBM Corp., Armonk, NY, USA) software.

\section{Results}

Patients and tumor characteristics. The current study included available data (Table I) from 191 patients with newly diagnosed BC and SLN metastasis who underwent an ALND procedure. The median patient age was 59.5 years (range: $30-$ 87 years). The median tumor size was $1.8 \mathrm{~cm}$ (range: $0.5-8$ $\mathrm{cm})$. The incidence of luminal and non-luminal tumors was $90.6 \%$ and $9.4 \%$, respectively. Incidence as per receptor status was as follows: Triple-negative $=5.2 \%, \mathrm{ER}^{-} \mathrm{PR}^{-} \mathrm{HER} 2^{+}=4.2 \%$, $\mathrm{ER}^{+} \mathrm{PR}^{-} \mathrm{HER}^{-}=10.9 \%, \mathrm{ER}^{+} \mathrm{PR}^{-} \mathrm{HER}^{+}=5.23 \%, \mathrm{ER}^{+} \mathrm{PR}^{+}$ $\mathrm{HER}^{-}=61.2 \%$, and triple-positive $=14.1 \%$.

The median number of SLNs retrieved was 1.6 (range=14 ), and the average number of positive SLNs was 1.4 (range=1-4). More than 3 SLNs were removed in only 29 (15.1\%) cases. Among all patients, 146 (76.4\%) exhibited metastasis in a single SLN, whereas the other $45(23.6 \%)$ 


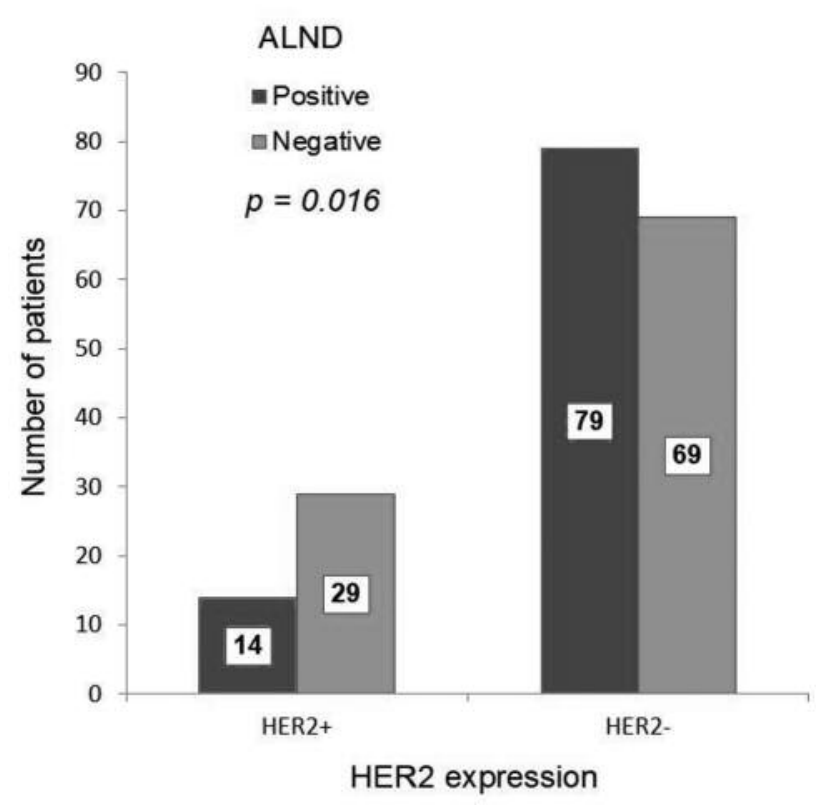

Figure 1. Frequency of further axillary metastases in human epidermal growth factor receptor 2 (HER2)-positive and HER2-negative cases (odds ratio=0.4; $p=0.016$ ). ALND: Axillary lymph node dissection.

had two or fewer positive SLNs. Sixteen patients (8.4\%) had micrometastasis, whereas $175(91.6 \%)$ had macrometastasis in the SLN. The median number of non SLNs retrieved was 14.7 (range=2-39). The number of positive non SLNs ranged from 1 (in $36 \%$ of patients) to 13 . At least 1 positive non SLN was found in $93(48.6 \%)$ patients, whereas the other 98 $(51.3 \%)$ presented with disease-free non SLNs.

Prognostic factors associated with the presence of at least one additional metastatic non-SLN. There was no association between age and non-SLN metastasis by the $t$ test $(p=0.3)$. Lower age was protective vis-à-vis axillary LN status (statistically insignificant), when considering patients below 40 [odds ratio $(\mathrm{OR})=0.33$ ], $45(\mathrm{OR}=0.67)$, or 50 years $(\mathrm{OR}=0.7)$ of age. Furthermore, the chi-square test showed age $<50$ years was significantly associated $(p=0.002)$ with a sentinel node ratio of 1 , indicating a $70 \%$ lower risk of non SLN metastasis compared to those aged $>50$ years $(\mathrm{OR}=0.3)$.

No differences were revealed in the invasive tumor size distribution (pT) and non-SLN metastasis, either by chisquare test or by univariate binary logistic regression. However, since a greater proportion of $\mathrm{T} 1 \mathrm{c}$ invasive $\mathrm{BC}$ $(50.7 \%)$ occurred among cases, this threshold stage had a 2.3-fold higher risk $(\mathrm{OR}=2.3)$ of $\mathrm{SNR}>0.67$ (dichotomized value of $0.67 v s$. other). In this context, considering a cutoff point of 0.67 , SNR was a strong predictor of non-SLN

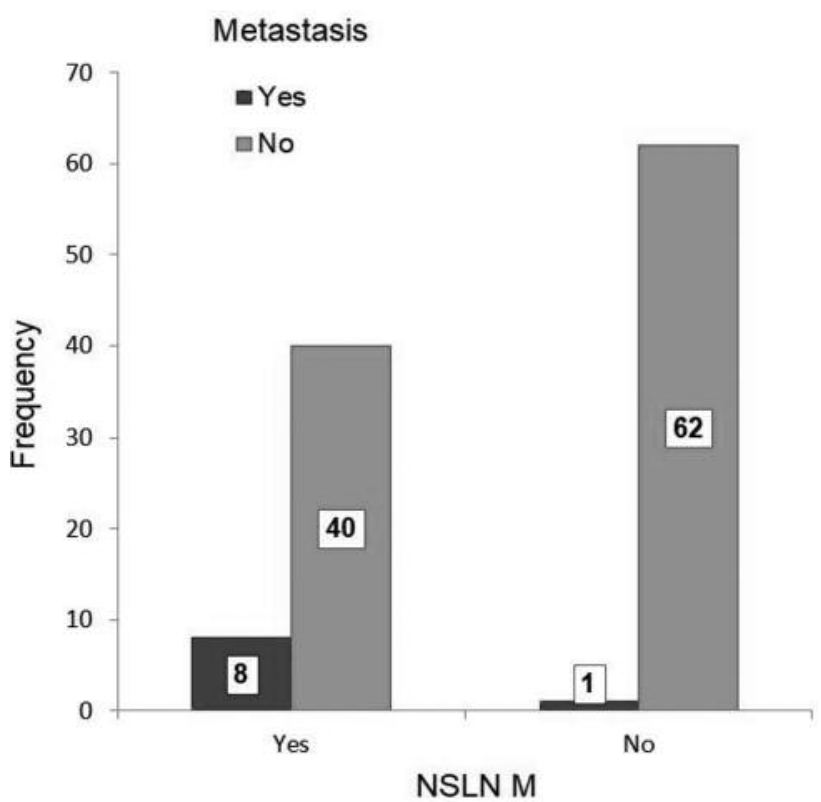

Figure 2. Prevalence of distant metastases in axillary lymph node dissection (ALND)-positive and ALND-negative cases (odds ratio=12.4, $95 \%$ confidence interval $=1.5-103 ; p=0.004)$. NSLNM: Non-sentinel lymph node metastasis.

Table II. Molecular subtype distribution among axillary lymph node dissection (ALND)-positive and ALND-negative cases (Chi-square test, $p=0.03)$.

\begin{tabular}{lccr}
\hline & \multicolumn{2}{c}{ ALND, n (\%) } & \multirow{2}{*}{ Total } \\
\cline { 2 - 3 } Subtype & $\begin{array}{c}\text { Positive } \\
(48.7 \%)\end{array}$ & $\begin{array}{c}\text { Negative } \\
(51.3 \%)\end{array}$ \\
\hline Basal & $5(5.4 \%)$ & $5(5.1 \%)$ & $10(5.2 \%)$ \\
HER2 & $0(0 \%)$ & $8(8.2 \%)$ & $8(4.2 \%)$ \\
Luminal A & $60(64.5 \%)$ & $52(53.1 \%)$ & $112(58.6 \%)$ \\
Luminal B HER2 & $14(15.1 \%)$ & $10(10.2 \%)$ & $24(12.6 \%)$ \\
Luminal B HER2 & $14(15.1 \%)$ & $23(23.5 \%)$ & $37(19.4 \%)$ \\
Total & $93(100 \%)$ & $98(100 \%)$ & $191(100 \%)$ \\
\hline
\end{tabular}

HER2: Human epidermal growth factor receptor 2.

metastasis in the chi-square test $(p=0.032)$, with a 2.5 -fold higher risk in patients with $\mathrm{SNR}>0.67(\mathrm{OR}=2.55)$.

Tumor grade did not predict axillary LN status either by a Chi-squared distribution or by the univariate binary logistic regression model. However, patients with a higher tumor grade were more likely to have SNR $>0.67$ across the grade progression, although this association was not statistically significant $(p>0.05)$.

In the 93 patients with further axillary LN involvement, those with luminal A tumors had the highest metastatic rate 


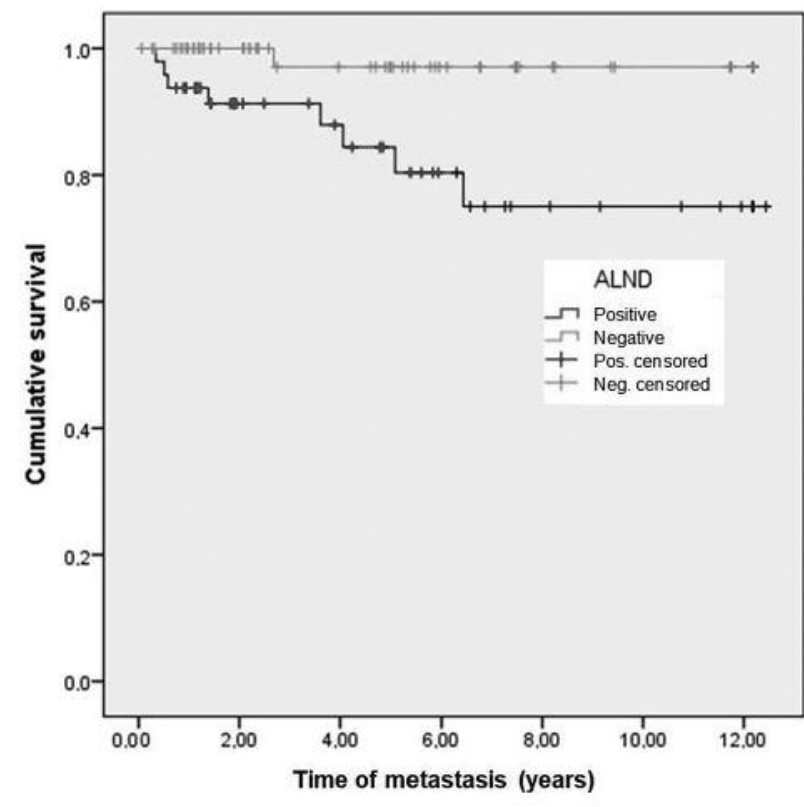

Figure 3. Kaplan-Meier cumulative survival analysis of two subgroups adjusted for nodal status: axillary lymph node dissection (ALND)positive and ALND-negative cases.

(64.5\%), followed by luminal B $(15 \%)$, HER $2^{+}$luminal B $(15 \%)$, basal $(5.3 \%)$, and non-luminal HER $2^{+}(0 \%)$ tumors, with a statistically significant distribution $(p=0.03)$ (Table II). However, the molecular subtype designation did not significantly affect study outcomes. Although non-luminal HER $2^{+}$tumors had a lower trend for association non-SLN metastasis, we were unable to generate an OR value for this subgroup due to insufficient data. The luminal BC group had a three-fold higher risk of positive axillary $\mathrm{LN}$ metastasis compared to that of the non-luminal subtypes $(\mathrm{OR}=2.67$, $p=0.06$, statistically insignificant).

On the other hand, the evaluation based on HER2 overexpression revealed that both HER2-enriched and luminal/HER2 subtypes had a relatively limited risk of additional lymphatic spread (OR=0.4; $p=0.016)$. Thus, HER2 may be a reliable and significant protective factor for axillary involvement (Figure 1). Among the six combined receptor variables, only the $\mathrm{ER}^{+} \mathrm{PR}^{-} \mathrm{HER} 2^{-}$profile was strongly related to positive axillary $\mathrm{LN}$ status $(\mathrm{OR}=2.95$, $p=0.027$ ), while a linear trend was observed for the $\mathrm{ER}^{+} \mathrm{PR}^{+}$ HER2 ${ }^{-}$subtypes, but without significance $(\mathrm{OR}=2.14$, $p=0.17$ ). There was no significant association between NSLNM and multifocality, lymphovascular invasion, or size of metastasis in SLN $(p>0.05)$, which might be attributed to the small sample size. Long-term remote metastasis rates in the axillary LN-positive and -negative groups were 16.7\% $(n=8 / 48)$ and $1.6 \%(1 / 63)$, respectively. Interestingly, this association was strong $[\mathrm{OR}=12.4 ; 95 \%$ confidence interval
$(C I)=1.5-103 ; p=0.004]$, confirming that absence of lymphatic spread beyond SLNs was significantly protective, and lowered the risk of distant recurrence by more than $90 \%$ $(\mathrm{OR}=0.08 ; 95 \% \mathrm{CI}=0.01-0.7 ; p=0.02)$ (Figure 2). KaplanMeier analysis for the two subgroups adjusted for nodal status showed that the cumulative survival in patients with axillary LN-positive BC declined linearly over time, indicating a constant mortality rate (Figure 3 ).

\section{Discussion}

The axillary LN status is one of the best independent prognostic factors for disease-free and overall survival in $\mathrm{BC}$, although some tumors are already systemic without axillary LN involvement (24). Furthermore, in $40-70 \%$ of patients with early BC, the SLN is the only involved axillary $\mathrm{LN}$, implying that approximately half of SLN-positive patients may undergo ALND unnecessarily, with no benefit therapeutically or for staging accuracy (25-26). These results suggest that there is a subset of low-risk SLN-positive patients in whom ALND may be unnecessary (27).

In majority of patients with pathologically positive SLNs, completion ALND is recommended by the American Society of Clinical Oncology Guidelines and the National Comprehensive Cancer Network guidelines. However, the recent ACSOG Z-011 trial demonstrated that patients with limited SLN positivity (1-2 SLNs) treated with breastconserving surgery, adjuvant whole breast irradiation, and systemic therapy did not benefit from completion ALND (28). Breast cancer surgeons are now debating the requirement for axillary clearance in all SLN-positive cases, proposing a more selective approach based on individual risk (29).

It has been identified that tumor and nodal characteristics collectively affect non-SLN metastasis status. The agerelated pattern of $\mathrm{LN}$ involvement may play a key role in $\mathrm{BC}$ outcome, therefore influencing the choice of treatment. However, there is controversy concerning the definition of younger and older patients, reflecting the inherent heterogeneity of BC. Some studies have reported an inverse association between age and LN metastasis after controlling for other variables, indicating higher $\mathrm{BC}$ aggressiveness in younger women, probably due to higher endogenous estrogen levels (30-31). On the other hand, Holberg et al. found a non-linear correlation between age and axillary LN status, and reported that the incidence of positive axillary LNs, adjusted for tumor size, declined in patients aged $>59$ years at diagnosis, but also appeared to be lower in women aged $<40$ years (32). In contrast, in a large cohort of patients from the University Hospital of Leuven database, women aged $>70$ years were more likely to be LN-positive with increasing age (33). Interestingly, in older women, the effect of age interacted with tumor size, suggesting that increasing age was associated with a higher risk of $\mathrm{LN}$ involvement 
mainly in patients with small tumors, whereas for those with larger tumors, the effect of age on nodal status was similar between the younger and older patients.

Our results need further confirmation, and in this regard, we are conducting separate analyses of our datasets to explore the association between age and metastastic potential in greater detail.

Overall tumor size is e a significant predictor of residual axillary disease and survival outcomes $(34,35)$. In our study, we did not identify a statistically significant association between tumor size and non-SLN metastasis, possibly due to the smaller sample size and fewer individuals with non-SLN metastasis $(n=93)$. However, we identified an increasing trend for $\mathrm{SNR}>0.67(\mathrm{OR}=2.3)$, and a higher rate of further nodal involvement $(\mathrm{OR}=2.55, p=0.032)$ among patients with T1c BC. This well-established relationship may not hold in a small subset of cancers with more aggressive and invasive phenotypes. Distant spread has been considered a late event in tumor progression, although recent studies have suggested that for some tumors, acquisition of metastatic potential may be an early event, even in the absence of detectable primary tumor $(36,37)$.

We sought to determine the predictive value of histological grade and nodal involvement in $\mathrm{BC}$, as reported by other studies $(38,39)$. Although literature evidence suggests that grade assessment may accurately predict the biological behavior of invasive cancer, in the present study, the Nottingham Grading System showed a limited prognostic association with the rate of non-SLN metastasis. However, these results imply that multifactorial indices such as combined steroid receptor expression or molecular subtyping have predictive and prognostic value in $\mathrm{BC}$.

$\mathrm{BC}$ is a heterogeneous disease with substantial variation in both molecular and clinical characteristics, and a new molecular-driven integrated classification has been introduced. The novel biological analysis integrates molecular and clinical features to define five clusters with distinct clinical outcomes and provides new insights into the management of the disease (23). In the present study, we identified a correlation between lymphatic disease progression and luminal $\mathrm{BC}(\mathrm{OR}=2.67, p=0.06)$, implying that nodal status may help determine individualized treatment. In contrast, in several studies evaluating outcome among different tumor subtypes, the risk of distant recurrence was highest for basal and non-luminal HER $2^{+}$disease, and lowest for $\mathrm{ER}^{+}$luminal disease (40-42). The difference between the risk of nodal and distant metastasis among tumor subtypes may indicate that hematogenous spread to distant sites occurs separately and in parallel with lymphatic spread to lymph nodes, rather than sequentially from lymph node metastases. Alternatively, different tumor types may have different preferred routes of metastasis: $\mathrm{ER}^{+}$tumors may disseminate via the lymphatics, while basal-like cancers may disseminate through the blood stream. The value of steroid receptor expression as a reliable predictor of axillary LN status is also controversial (7). Some studies have reported that ER and PR had no predictive value, whereas others have reported a lower risk of axillary $\mathrm{LN}$ metastasis in tumors negative for either receptor or for PR only $(31,43-45)$. Our findings are in line with the latter reports. Axillary LN invasion was least likely in those with $\mathrm{ER}^{-} \mathrm{PR}^{-} \mathrm{HER} 2^{+}(\mathrm{OR}=0.4 ; p=0.016)$ and most likely in those with $\mathrm{ER}^{+} \mathrm{PR}^{-} \mathrm{HER} 2^{-}(\mathrm{OR}=2.95, p=0.027)$ and $\mathrm{ER}^{+} \mathrm{PR}^{+} \mathrm{HER} 2^{-}(\mathrm{OR}=2.14, p=0.17) \mathrm{BC}$, probably reflecting a crosstalk between ER/PR and HER2, influencing tumor cell migration and $\mathrm{LN}$ invasion. Thus, the correlation between joint ER/PR status and non-SLN metastasis requires further exploration; however, it is conceivable that after controlling for tumor and patient characteristics, the presence of intact estrogen and progesterone signaling pathways favors disease progression (30).

Chi-square analysis indicated a significant association between the SNR and non-SLN metastasis, and a 2.5 -fold higher risk in patients characterized by a SNR 0.67 $(\mathrm{OR}=2.55, p=0.032)$. These results indicate that $\mathrm{SNR}$ is a potent predictor of non-SLN metastasis, and may be used to risk-stratify patients with favorable tumor characteristics and a low probability of residual disease in axilla. Many recent studies have suggested that the SNR may predict prognosis more precisely, and is a candidate parameter for inclusion in the staging system, regardless of the number of metastastic axillary nodes (based on the American Joint Committee on Cancer, TNM breast cancer staging) (46). Several studies have reported that a significant SNR cutoff value for $\mathrm{BC}$ is about $0.5-0.7$, but further validation of this variable is required, because patients classified based on the same nodal staging category did not display similar prognosis in both disease-free survival and OS $(47,48)$. Since SNR was most significantly related to recurrence and mortality, axillary dissection is recommended in patients with BC with advanced axillary metastasis $(49,50)$; aggressive adjuvant treatment and close follow-up are also indicated.

Nodal status remains one of the primary prognostic discriminants in patients with $\mathrm{BC}$, and is of great value as an independent predictor of distant disease development, as we report in our study. Although several institutional case series have differed in patient selection, follow-up, type of surgery and adjuvant therapies, they have consistently shown that the percentage of positive lymph nodes is a significant indicator of survival in women with axillary metastases on final pathology (51). In the present study, we revealed a correlation between lymphatic disease progression and increased risk of metastatic spread, implying that nodal status reflects the intrinsic biological properties of a primary tumor (52). On the other hand, further research is required to establish whether there are 
reproducible organ-distinct patterns of distant recurrence across the different molecular subtypes, as well as the relationship with nodal involvement.

This study has several limitations. Firstly, this was a retrospective study, with the possibility of unrecognized bias. Secondly, only partial long-term survival data were available for predictive analysis. Thirdly, recent studies about LN ratio were limited, and there is heterogeneity in cutoff values used across the literature. Finally, we did not include other predictors of axillary LN status, such as tumor localization within the breast, vascularization, lymphangiogenesis, and biomarkers of axillary LN involvement. Therefore, further follow-up studies are required. In our study, sentinel nodes were the only tumor-involved nodes in $50 \%$ of the patients Our results indicated that nodal ratio and breast cancer subtype as determined by ER, PR, and HER2 status significantly predicted the likelihood of additional nodal metastasis. The percentage of positive SLNs was an independent risk factor of tumor local aggressiveness and HER2 overexpression (luminal B HER2 ${ }^{+}$and HER2 type) was a reliable and significant protective factor for axillary involvement.

In addition, a higher incidence of non-SLN metastasis was associated with increasing age and histological grade, although this did not reach statistical significance possibly due to small sample size. Further larger clinical trials to identify predictors of non-SLN metastasis are indicated. The validation of these predictors in prospective studies may enable approximately half of patients with early-stage BC with positive SLN to be staged with SLNB alone while avoiding the morbidity of unnecessary ALND and thus guiding axillary treatment considerations. Until the results of further larger randomized studies comparing OS, disease-free survival, locoregional control, and morbidity of ALND vs. no ALND after positive SLN are available, the current recommendation is to proceed with completion ALND in patients with SLN metastasis.

Numerous risk factors for relapse in BC have been established, including tumor size, nodal status, hormone receptor status, and grade, and clinical application of molecular signatures may be helpful in predicting tumor behavior, guiding practice, and offering personalized treatments. The recognition of subtype-specific differences in short- and long-term prognosis may lead to tailored follow-up programs after first-line therapy, and prevent disease over- or under-treatment.

\section{Acknowledgements}

The Authors thank all participating patients and consultants and the Tor Vergata Breast Cancer Unit. The views expressed are those of the Authors and not necessarily those of the NHS, the National Institute for Health Research, or the Department of Health.

\section{References}

1 Dowsett M, Cuzick J, Wale C, Forbes J, Mallon EA, Salter J, Quinn E, Dunbier A, Baum M, Buzdar A, Howell A, Bugarini R, Baehner FL and Shak S: Prediction of risk of distant recurrence using the 21-gene recurrence score in node-negative and node-positive postmenopausal patients with breast cancer treated with anastrozole or tamoxifen: a TransATAC study. J Clin Oncol 28: 1829-1834, 2010.

2 Bevilacqua JL, Kattan MW, Fey JV, Cody HS 3rd, Borgen PI and Van Zee KJ: Doctor, what are my chances of having a positive sentinel node? A validated nomogram for risk estimation. J Clin Oncol 25: 3670-3679, 2007.

3 Van Calster B, Vanden Bempt I, Drijkoningen M, Pochet N, Cheng J, Van Huffel S, Hendrickx W, Decock J, Huang HJ, Leunen K, Amant F, Berteloot P, Paridaens R, Wildiers H, Van Limbergen E, Weltens C, Timmerman D, Van Gorp T, Smeets A, Van den Bogaert W, Vergote I, Christiaens MR and Neven P: Axillary lymph node status of operable breast cancers by combined steroid receptor and HER-2 status: triple-positive tumours are more likely lymph node positive. Breast Cancer Res Treat 113: 181-187, 2009.

4 Ross JS, Fletcher JA, Linette GP, Stec J, Clark E, Ayers M, Symmans WF, Pusztai L and Bloom KJ: The HER-2/neu gene and protein in breast cancer 2003: biomarker and target of therapy. Oncologist 8: 307-325, 2003.

5 Paik S, Hazan R, Fisher ER, Sass RE, Fisher B, Redmond C, Schlessinger J, Lippman ME and King CR: Pathologic findings from the National Surgical Adjuvant Breast and Bowel Project: prognostic significance of ERBB-2 protein overexpression in primary breast cancer. J Clin Oncol 8: 103-112, 1990.

6 Lee AV, Cui X and Oesterreich S: Cross-talk among estrogen receptor, epidermal growth factor, and insulin-like growth factor signaling in breast cancer. Clin Cancer Res 7(12 Suppl): 4429s4435s, 2001.

7 Patani NR, Dwek MV and Douek M: Predictors of axillary lymph node metastasis in breast cancer: a systematic review. Eur J Surg Oncol 33: 409-419, 2007.

8 Toshikawa C, Koyama Y, Nagahashi M, Tatsuda K, Moro K, Tsuchida J, Hasegawa M, Niwano T, Manba N, Ikarashi M, Kameyama H, Kobayashi T, Kosugi S and Wakai T: Predictive factors for non-sentinel lymph node metastasis in the case of positive sentinel lymph node metastasis in two or fewer nodes in breast cancer. J Clin Med Res 7: 620-625, 2015.

9 Reyal F, Rouzier R, Depont-Hazelzet B, Bollet MA, Pierga JY, Alran S, Salmon RJ, Fourchotte V, Vincent-Salomon A, SastreGarau X, Antoine M, Uzan S, Sigal-Zafrani B and De Rycke Y: The molecular subtype classification is a determinant of sentinel node positivity in early breast carcinoma. PLoS One 6: e20297, 2011.

10 Moosavi SA, Abdirad A, Omranipour R, Hadji M, Razavi AE and Najafi M: Clinicopathologic features predicting involvement of non-sentinel axillary lymph nodes in Iranian women with breast cancer. Asian Pac J Cancer Prev 15: 7049-7054, 2014.

11 Lu X, Lu X, Wang ZC, Iglehart JD, Zhang X and Richardson AL: Predicting features of breast cancer with gene expression patterns. Breast Cancer Res Treat 108: 191-201, 2008.

12 Crabb SJ, Cheang MC, Leung S, Immonen T, Nielsen TO, Huntsman DD, Bajdik CD and Chia SK: Basal breast cancer molecular subtype predicts for lower incidence of axillary lymph node metastases in primary breast cancer. Clin Breast Cancer 8: 249-256, 2008 
13 Lee JH, Kim SH, Suh YJ, Shim BY and Kim HK: Predictors of axillary lymph node metastases (ALNM) in a Korean population with T1-2 breast carcinoma: triple-negative breast cancer has a high incidence of ALNM irrespective of the tumor size. Cancer Res Treat 42: 30-36, 2010.

14 Chu KU, Turner RR, Hansen NM, Brennan MB, Bilchik A and Giuliano AE: Do all patients with sentinel node metastasis from breast carcinoma need complete axillary node dissection? Ann Surg 229: 536-541, 1999.

15 Turner RR, Chu KU, Qi K, Botnick LE, Hansen NM, Glass EC and Giuliano AE: Pathologic features associated with nonsentinel lymph node metastases in patients with metastatic breast carcinoma in a sentinel lymph node. Cancer 89: 574-581, 2000.

16 Schrenk P, Rieger R, Shamiyeh A and Wayand W: Morbidity following sentinel lymph node biopsy versus axillary lymph node dissection for patients with breast carcinoma Cancer 88 : 608-614, 2000.

17 Lucci A, McCall LM, Beitsch PD, Whitworth PW, Reintgen DS, Blumencranz PW, Leitch AM, Saha S, Hunt KK, Giuliano AE and American College of Surgeons Oncology Group: Surgical complications associated with sentinel lymph node dissection (SLND) plus axillary lymph node dissection compared with SLND alone in the American College of Surgeons Oncology Group Trial Z0011. J Clin Oncol 25: 3657-3663, 2007.

18 Ashikaga T, Krag DN, Land SR, Julian TB, Anderson SJ, Brown AM, Skelly JM, Harlow SP, Weaver DL, Mamounas EP, Costantino JP and Wolmark N: National Surgical Adjuvant Breast, Bowel Project. Morbidity results from the NSABP B-32 trial comparing sentinel lymph node dissection versus axillary dissection. J Surg Oncol 102: 111-118, 2010.

19 Goldhirsch A, Wood WC, Coates AS, Gelber RD, Thürlimann B, Senn HJ and Panel members: Strategies for subtypes dealing with the diversity of breast cancer: highlights of the St. Gallen International Expert Consensus on the Primary Therapy of Early Breast Cancer 2011. Ann Oncol 22: 1736-1747, 2011.

20 Edge SB, Byrd DR, Compton CC, Fritz AG, Greene FL and Trotti A: AJCC Cancer Staging Manual (7th ed). New York, NY: Springer; 2010.

21 Edge SB, Byrd DR, Compton CC, Fritz AG, Greene FL and Trotti A: Part VII: Breast. In: AJCC Cancer Staging Manual (7th ed). Edge SB, Byrd DR, Compton CC, Fritz AG, Greene FL and Trotti A (eds.). New York, Springer, pp. 345-376, 2010.

22 Contesso G, Mouriesse H, Friedman S, Genin J, Sarrazin D and Rouesse J: The importance of histologic grade in long-term prognosis of breast cancer: a study of 1,010 patients, uniformly treated at the Institut Gustave-Roussy. J Clin Oncol 5: 13781386, 1987.

23 Goldhirsch A, Winer EP, Coates AS, Gelber RD, Piccart-Gebhart M, Thürlimann B, Senn HJ and Panel members: Personalizing the treatment of women with early breast cancer: highlights of the St Gallen International Expert Consensus on the Primary Therapy of Early Breast Cancer 2013. Ann Oncol 24: 2206-2223, 2013.

24 Esteva FJ and Hortobagyi GN: Prognostic molecular markers in early breast cancer. Breast Cancer Res 6: 109-118, 2004.

25 Rahusen FD, Torrenga H, van Diest PJ, Pijpers R, van der Wall E, Licht $J$ and Meijer S: Predictive factors for metastatic involvement of nodes in patients with breast cancer. Arch Surg 136: 1059-1063, 2001.

26 Barranger E, Coutant C, Flahault A, Delpech Y, Darai E and Uzan S: An axilla scoring system to predict non-sentinel lymph node status in breast cancer patients with sentinel lymph node involvement. Breast Cancer Res Treat 91: 113-119, 2005.

27 Naik AM, Fey J, Gemignani M, Heerdt A, Montgomery L, Petrek J, Port E, Sacchini V, Sclafani L, VanZee K, Wagman R, Borgen PI and Cody HS 3rd: The risk of axillary relapse after sentinel lymph node biopsy for breast cancer is comparable with that of axillary lymph node dissection: a follow-up study of 4008 procedures. Ann Surg 240: 462-468, 2004.

28 Giuliano AE, McCall L, Beitsch P, Whitworth PW, Blumencranz P, Leitch AM, Saha S, Hunt KK, Morrow M and Ballman K: Locoregional recurrence after sentinel lymph node dissection with or without axillary dissection in patients with sentinel lymph node metastases: the American College of Surgeons Oncology Group Z0011 randomized trial. Ann Surg 252: 426432, 2010.

29 Gatzemeier W and Mann GB: Which sentinel lymph-node (SLN) positive breast cancer patient needs an axillary lymph-node dissection (ALND)? ACOSOG Z0011 results and beyond. Breast 22: 211-216, 2013.

30 Gann PH, Colilla SA, Gapstur SM, Winchester DJ and Winchester DP: Factors associated with axillary lymph node metastasis from breast carcinoma: descriptive and predictive analyses. Cancer 86: 1511-1519, 1999.

31 Gajdos C, Tartter PI and Bleiweiss IJ: Lymphatic invasion, tumor size, and age are independent predictors of axillary lymph node metastases in women with T1 breast cancers. Ann Surg 230: 692-696, 1999.

32 Holmberg L, Pontén J and Adami HO: The biology and natural history of breast cancer from the screening perspective. World J Surg 13: 25-30, 1989.

33 Hwang RF, Krishnamurthy S, Hunt KK, Mirza N, Ames FC, Feig B, Kuerer HM, Singletary SE, Babiera G, Meric F, Akins JS, Neely J and Ross MI: Clinicopathologic factors predicting involvement of nonsentinel axillary nodes in women with breast cancer. Ann Surg Oncol 10: 248-254, 2003.

34 Rosenberg J, Chia YL and Plevritis S: The effect of age, race, tumor size, tumor grade, and disease stage on invasive ductal breast cancer survival in the U.S. SEER database. Breast Cancer Res Treat 89: 47-54, 2005.

35 Wo JY, Chen K, Neville BA, Lin NU and Punglia RS: Effect of very small tumor size on cancer-specific mortality in nodepositive breast cancer. J Clin Oncol 29: 2619-2627, 2011.

36 Engel J, Eckel R, Kerr J, Schmidt M, Fürstenberger G, Richter R, Sauer H, Senn HJ and Hölzel D: The process of metastasisation for breast cancer. Eur J Cancer 39(12): 17941806, 2003.

37 van 't Veer LJ, Dai H. van de Vijver MJ, He YD, Hart AA, Mao M, Peterse HL, van der Kooy K, Marton MJ, Witteveen AT, Schreiber GJ, Kerkhoven RM, Roberts C, Linsley PS, Bernards $\mathrm{R}$ and Friend $\mathrm{SH}$ : Gene expression profiling predicts clinical outcome of breast cancer. Nature 415: 530-536, 2002.

38 Rakha EA, Reis-Filho JS, Baehner F, Dabbs DJ, Decker T, Eusebi V, Fox SB, Ichihara S, Jacquemier J, Lakhani SR, Palacios J, Richardson AL, Schnitt SJ, Schmitt FC, Tan PH, Tse GM, Badve $S$ and Ellis IO: Breast cancer prognostic classification in the molecular era: the role of histological grade. Breast Cancer Res 12: 207, 2010.

39 Silverstein MJ, Skinner KA and Lomis TJ: Predicting axillary nodal positivity in 2282 patients with breast carcinoma. World $\mathbf{J}$ Surg 25: 767-772, 2001. 
40 Sørlie T, Perou CM, Tibshirani R, Aas T, Geisler S, Johnsen H, Hastie T, Eisen MB, van de Rijn M, Jeffrey SS, Thorsen T, Quist $\mathrm{H}$, Matese JC, Brown PO, Botstein D, Lønning PE and Børresen-Dale AL: Gene expression patterns of breast carcinomas distinguish tumor subclasses with clinical implications. Proc Natl Acad Sci USA 98: 10869-10874, 2001.

41 Sorlie T, Tibshirani R, Parker J, Hastie T, Marron JS, Nobel A, Deng S, Johnsen H, Pesich R, Geisler S, Demeter J, Perou CM, Lønning PE, Brown PO, Børresen-Dale AL and Botstein D: Repeated observation of breast tumor subtypes in independent gene expression data sets. Proc Natl Acad Sci USA 100: 84188423, 2003.

42 Buonomo OC, Caredda E, Portarena I, Vanni G, Orlandi A, Bagni C, Petrella G, Palombi L and Orsaria P: New insights into the metastatic behavior after breast cancer surgery, according to well-established clinicopathological variables and molecular subtypes. PLoS One 12: e0184680, 2017.

43 Chua B, Ung O, Taylor R and Boyages J: Frequency and predictors of axillary lymph node metastases in invasive breast cancer. ANZ J Surg 71: 723-728, 2001.

44 Ravdin PM, De Laurentiis M, Vendely $\mathrm{T}$ and Clark GM: Prediction of axillary lymph node status in breast cancer patients by use of prognostic indicators. J Natl Cancer Inst 86: 1771$1775,1994$.

45 Viale G, Maiorano E, Pruneri G, Mastropasqua MG, Valentini S, Galimberti V, Zurrida S, Maisonneuve P, Paganelli G and Mazzarol G: Predicting the risk for additional axillary metastases in patients with breast carcinoma and positive sentinel lymph node biopsy. Ann Surg 241: 319-325, 2005.

46 Woodward WA, Vinh-Hung V, Ueno NT, Cheng YC, Royce M, Tai P, Vlastos G, Wallace AM, Hortobagyi GN and Nieto Y: Prognostic value of nodal ratios in node-positive breast cancer. J Clin Oncol 24: 2910-2916, 2006.
47 Vinh-Hung V, Verkooijen HM, Fioretta G, Neyroud-Caspar I, Rapiti E, Vlastos G, Deglise C, Usel M, Lutz JM and Bouchardy $\mathrm{C}$ : Lymph node ratio as an alternative to $\mathrm{pN}$ staging in nodepositive breast cancer. J Clin Oncol 27: 1062-1068, 2009.

48 Hur $\mathrm{MH}$ and Ko S: Metastatic axillary node ratio predicts recurrence and poor long-term prognosis in patients with advanced stage IIIC (pN3) breast cancer. Ann Surg Treat Res 92: 340-347, 2017.

49 Kim SW, Choi DH, Huh SJ, Park W, Nam SJ, Kim SW, Lee JE, Im YH, Ahn JS and Park YH: Lymph node ratio as a risk factor for locoregional recurrence in breast cancer patients with 10 or more axillary nodes. J Breast Cancer 19: 169-175, 2016.

50 Whelan TJ, Olivotto IA, Parulekar WR, Ackerman I, Chua B, Nabid A, Vallis KA, White JR, Rousseau P, Fortin A, Pierce LJ, Manchul L, Chafe S, Nolan MC, Craighead P, Bowen J, McCready DR, Pritchard KI, Gelmon K, Murray Y, Chapman JA, Chen BE, Levine MN and 20 Study Investigators: Regional nodal irradiation in early-stage breast cancer. N Engl J Med 373: 307-316, 2015.

51 Lale Atahan I, Yildiz F, Ozyigit G, Sari S, Gurkaynak M, Selek $\mathrm{U}$ and Hayran $\mathrm{M}$ : Percent positive axillary lymph node metastasis predicts survival in patients with non-metastatic breast cancer. Acta Oncol 47: 232-238, 2008.

52 Madekivi V, Boström P, Aaltonen R, Vahlberg T and Salminen E: The sentinel node with isolated breast tumor cells or micrometastases. benefits and risks of axillary dissection. Anticancer Res 37(7): 3757-3762, 2017.

Received January 2, 2018

Revised February 6, 2018

Accepted February 13, 2018 